\title{
Metallography of Robonaut 2 Battery Spot Welds
}

James E. Martinez ${ }^{1}$, Lucie B. Johannes ${ }^{1}$, Sandeep Yayathi ${ }^{2}$, Joshua M. Figuered ${ }^{2}$, Zoran M. Bilc ${ }^{3}$

${ }^{1 .}$ Structural Engineering Division, NASA Johnson Space Center, Houston TX, USA

2. Software, Robotics and Simulation Division, NASA Johnson Space Center, Houston TX, USA

${ }^{3 .}$ Flight Operations Directorate, NASA Johnson Space Center, Houston TX, USA

Li-ion cells provide an energy dense solution for systems that require rechargeable electrical power. However, these cells can undergo thermal runaway, the point at which the cell becomes thermally unstable and results in hot gas, flame, electrolyte leakage, and in some cases explosion. The heat and fire associated with this type of event is generally violent and can subsequently cause damage to the surrounding system or present a dangerous risk to the personnel nearby. The space flight environment is especially sensitive to risks particularly when it involves potential for fire within the habitable volume of the International Space Station (ISS).

In larger battery packs such as Robonaut 2 (R2), numerous Li-ion cells are placed in parallel-series configurations to obtain the required stack voltage and desired run-time or to meet specific power requirements. This raises a second and less obvious concern for batteries that undergo certification for space flight use: the joining quality at the resistance spot weld of battery cells to component wires/leads and battery tabs, bus bars or other electronic components and assemblies.

Resistance spot welds undergo materials evaluation, visual inspection, conductivity (resistivity) testing, destructive peel testing, and metallurgical examination in accordance with applicable NASA Process Specifications. Welded components are cross-sectioned to ensure they are free of cracks or voids open to any exterior surface. Pore and voids contained within the weld zone but not open to an exterior surface, and are not determined to have sharp notch like characteristics, shall be acceptable [1].

Depending on requirements, some battery cells are constructed of aluminum canisters while others are constructed of steel. Process specific weld schedules must be developed and certified for each possible joining combination. The aluminum canisters' positive terminals were particularly difficult to weld due to a bi-metal strip that comes ultrasonically pre-welded by the manufacturer. This was further complicated as the maximum electrode force was limited to low-electrode force to prevent deflection of the aluminum can during welding. Other Li-ion cells are comprised of smaller diameter cylindrical steel canisters which are inherently capable of handling greater force from the electrodes. Allowing higherelectrode forces aids greatly in insuring a consistent resistance network for the weld.

Various strategies were used to include adding projections to the tabs, slotting the tabs, and developing special electrode shapes. Essential variables such as load, time, power, voltage, and current also needed to be optimized to produce robust and defect-free welds.

Overall lessons learned:

- Developing good jigs is critical to insure the parts and electrodes are planer to one another and the location of the weld sites remains accurate and repeatable.

- Maintaining strict control over materials is critical. Materials must be of a specific hardness and chemical composition to insure that a weld schedule is repeatable. 
- Accuracy of the die used to stamp the projections is critical and worth the investment.

- Proper seasoning of the electrodes is critical to producing consistent welds. Once the electrodes have been properly seasoned, cleaning/dressing should be avoided until it is absolutely necessary.

Reference:

[1] NASA PRC-0009 Resistance Spot Welding of Battery Assemblies.

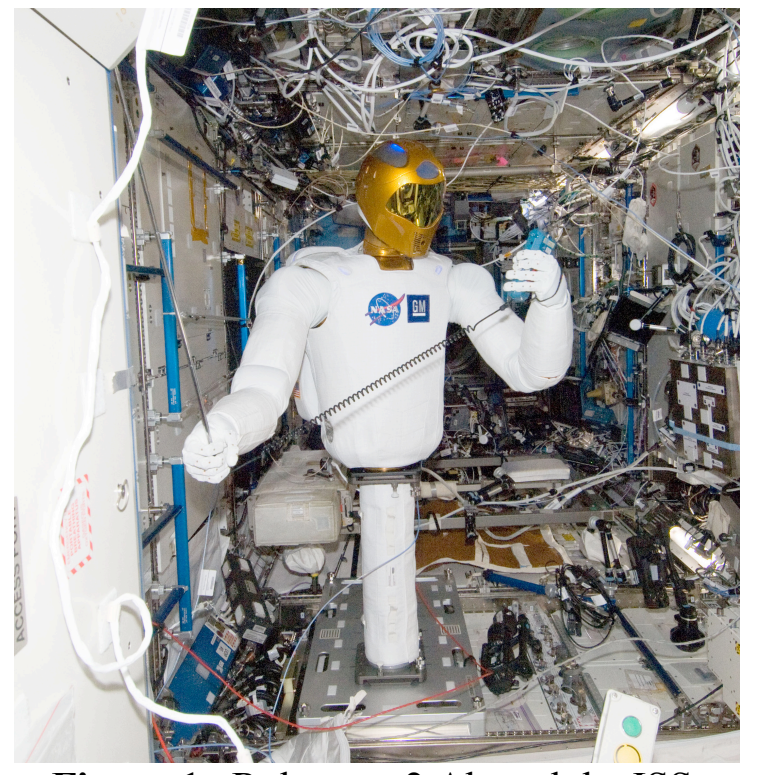

Figure 1. Robonaut 2 Aboard the ISS.

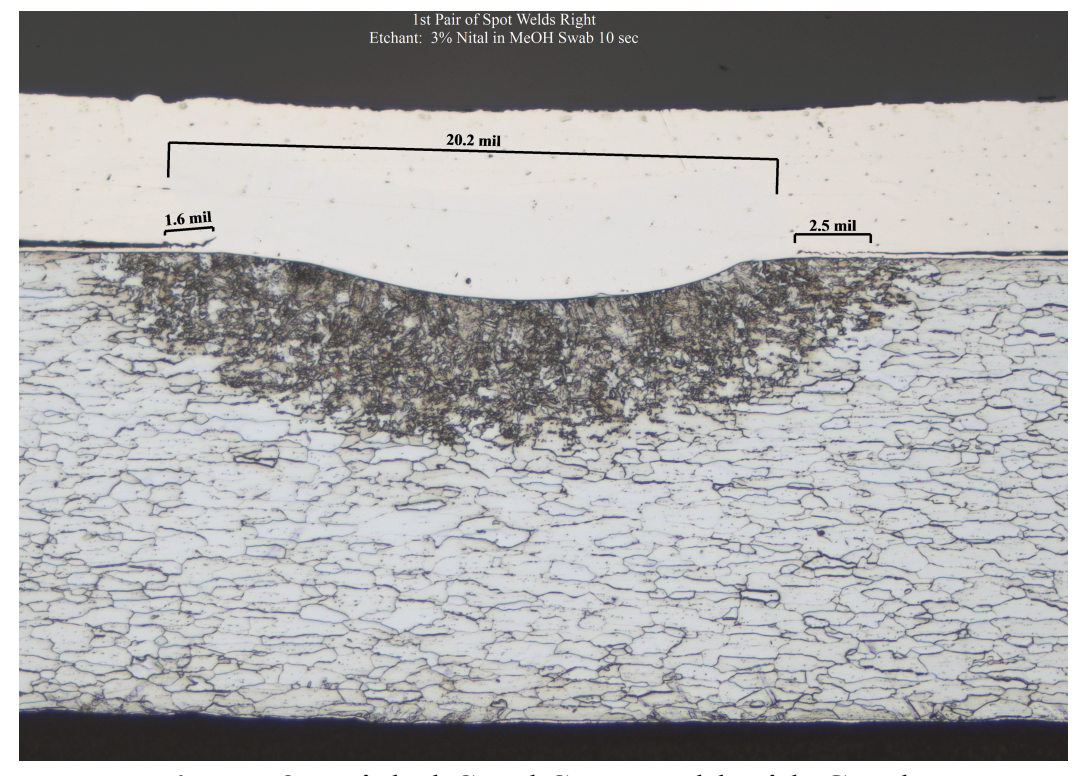

Figure 2. Nickel-Steel Spot Weld with Cracks on Both Sides of Interface.

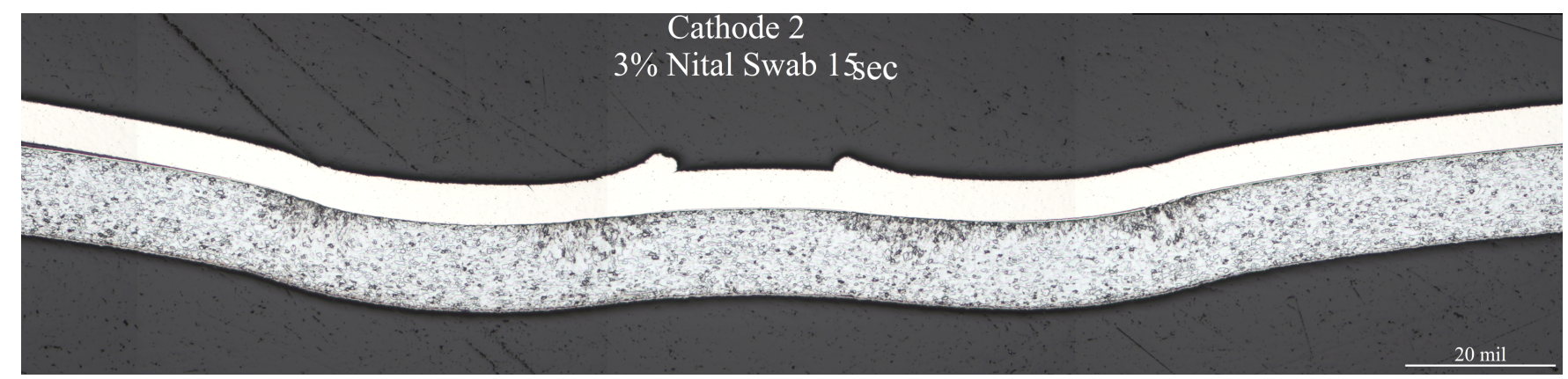

Figure 3. Nickel-Steel Cathode Showing Overload Deflection 